\begin{tabular}{|l|l|r|}
\hline & Al Fitrah & Analisi Problematika Anak Usia Dini 3-5 \\
Journal Of Early Childhood Islamic Education & Tahun Belum Mendapatkan Pendidikan \\
di PIAUD \\
ISSN : 2599-2287 E-ISSN : 2622-335X \\
Vol.2 No.2 Januari 2019
\end{tabular}

\title{
ANALISIS PROBLEMATIKA ANAK USIA 3-5 TAHUN BELUM MENDAPATKAN PENDIDIKAN DI PAUD
}

\begin{abstract}
Abstrak
Pendidikan Anak Usia Dini (PAUD) ini memberikan pondasi yang kuat bagi anak agar di kemudian hari anak bisa menjadi sosok manusia berkualitas yang nantinya tampil sebagai generasi penerus bangsa yang siap berkompetisi di era globalisasi. Tujuan penelitian ini, karena mengingat pentingnya Pendidikan Anak Usia Dini (PAUD) dalam meningkatkan perkembangan aspek-aspek yang dimilki oleh anak, maka hendaknya anak-anak dapat memperoleh pendidikan sejak dini paling tidak dalam rentang usia 3-5 Tahun yang mempersiapkan anak untuk menghadapi pendidikan dijenjang selanjutnya. Penelitian ini merupakan penelitian deskriptif kuantitatif. Tetapi berdasarkan survey yang telah dilakukan bahwa hal tersebut masih kurang menjadi perhatian, anak usia 3-5 Tahun masih 34\% belum mendapatkan/melaksanakan Pendidikan Anak Usia Dini (PAUD). Berdasarkan hasil survey tersebut yang membuktikan bahwa APK anak usia dini yang terdaftar sebagai siswa PAUD di Indonesia masih sangat minim, kesadaran akan pentingnya PAUD terhadap perkembangan anak usia dini belum sepenuhnya tumbuh, penyelenggaran program PAUD belum terrealisasikan secara sepenuhnya.
\end{abstract}

Kata kunci: Anak Usia Dini, Problematika PAUD

\author{
Ayu Wirda Nengsi \\ ayuwirdanengsih@gmail.com \\ IAIN Bengkulu
}

\section{Pendahuluan}

Pendidikan merupakan salah satu aspek yang dapat menentukkan kualitas kehidupan seseorang. Pendidikan anak dapat ditempuh melalui jalur formal, non formal, maupun informal. Pemerintah membuat beberapa program untuk memperbaiki mutu pendidikan nasional, salah satunya adalah program dalam bidang pendidikan yang dibuat khusus untuk anakanak pada usia dini yaitu Pendidikan Anak Usia Dini (PAUD). ${ }^{1}$

1 Eko Sri Lestari. Analisis Program Pendidikan Anak Usia Dini (Paud) Di Kota Semarang. (Skripsi S1 Fakultas Ilmu Sosial dan
PAUD diartikan sebagai usaha sadar dan terencana untuk mewujudkan suasana belajar dan proses pembelajaran kepada anak usia 0 hingga 6 tahun secara aktif dan kreatif agar memiliki kecerdasan emosional dan spiritual, serta kecerdasan intelektual yang diperlukan bagi dirinya, masyarakat, bangsa dan negara. Dalam PAUD diharapkan semua aspek perkembangan dapat berkembang secara optimal bukan hanya belajar secara akademik namun bermain sambil belajar untuk mengembangkan kemampuan yang sudah

Ilmu Politik, Universitas Diponegoro Semarang) hlm. 2 


\begin{tabular}{|r|l|r|}
\hline A1 Fitrah & Analisi Problematika Anak Usia Dini 3-5 \\
Journal Of Early Childhood Islamic Education & Tahun Belum Mendapatkan Pendidikan \\
di PIAUD \\
ISSN $:$ 2599-2287 E-ISSN $:$ 2622-335X \\
Vol.2 No.2 Januari 2019
\end{tabular}

dimiliki anak seperti perkembangan moral, agama, bahasa, kognitif, fisik motorik, dan sosial emosional dapat terintegrasi dengan baik. $^{2}$

Program Pendidikan Anak Usia Dini (PAUD) ini pada awalnya dibentuk karena tingkat kesadaran masyarakat akan pentingnya memberikan pendidikan anak sebelum jenjang sekolah dasar masih cukup rendah. Memberikan pendidikan untuk anak memang seharusnya diberikan sejak anak dalam usia dini untuk membentuk pribadi anak agar lebih siap menghadapi jenjang pendidikan selanjutnya. Pendidikan Anak Usia Dini (PAUD) ini memberikan pondasi yang kuat bagi anak agar di kemudian hari anak bisa menjadi sosok manusia berkualitas yang nantinya tampil sebagai generasi penerus bangsa yang siap

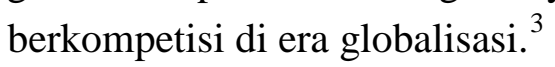

Mengingat pentingnya Pendidikan

Anak Usia Dini (PAUD) dalam meningkatkan perkembangan aspek-aspek yang dimilki oleh anak, maka hendaknya anak-anak dapat memperoleh pendidikan sejak dini paling tidak dalam rentang usia 3-5 yang mempersiapkan anak untuk menghadapi pendidikan dijenjang selanjutnya. Karena hal tersebut, maka penulis membahas tentang analisis usia 3-5 Tahun yang mendapat Pendidikan Anak Usia Dini (PAUD).

Dari latar belakang masalah diatas, maka penulis merumuskan permasalahan,

2 Novan Ardy. Konsep Dasar PAUD. (Yogyakarta : Gava Media, 2016) hlm. 1-3

3 Eko Sri Lestari. Analisis Program Pendidikan Anak Usia Dini (Paud) Di Kota Semarang. (Skripsi S1 Fakultas Ilmu Sosial dan Ilmu Politik, Universitas Diponegoro Semarang) hlm. 2 yaitu 1) Seberapa pentingnya Pendidikan Anak Usia Dini (PAUD) untuk anak usia 35 tahun?. 2) Bagaimana analisis problematika anak usia 3-5 tahun belum mendapatkan pendidikan di PAUD?. 3) Apa faktor penyebab 34\% anak usia 3-5 tahun belum mendapatkan pendidikan di PAUD?

\section{Metode Penelitian}

Jenis penelitian ini adalah field research (penelitian lapangan) yaitu penelitian mendalam mencakup keseluruhan yang terjadi di lapangan, dengan tujuan untuk mempelajari secara mendalam tentang latar belakang keadaan sekarang. ${ }^{4}$ Metode penelitian pada dasarnya merupakan cara ilmiah untuk mendapatkan data dengan tujuan dan kegunaan tertentu. ${ }^{5}$ Metode penelitian merupakan hal yang penting dalam melakukan penelitian. Dalam penelitian ini metode yang digunakan adalah metode deskriptif. Dalam operasionalnya, metode deskriptif kuantitatif digunakan sebagai proses penelitian yang menghasilkan data deskriptif baik berupa kata-kata (ungkapan) tertulis atau lisan yang diperoleh langsung dari lapangan lalu dianalisis dengan hitungan sederhana untuk mendapatkan persentase angka.

\section{Kajian Teori}

\section{Pentingnya Pendidikan Anak Usia Dini (PAUD) Untuk Usia 3-5 Tahun}

Masa usia dini merupakan periode emas (golden age) bagi perkembangan anak

4 Burhan Bungin, Metodologi Penelitian Kualitatif,(Jakarta: Rajawali Pers, 2010), hlm. 19.

5 Sugiyono, Metode PenelitianKuantitatif Kualitatif dan $R$ dan $D$, Cetakan Ke-13,(Bandung: Alfabeta, 2011), hlm. 2. 


\begin{tabular}{|c|c|c|}
\hline & $\begin{array}{l}\text { A1 Fitrah } \\
\text { Journal Of Early Childhood Islamic Education } \\
\text { ISSN : 2599-2287 E-ISSN : 2622-335X } \\
\text { Vol.2 No.2 Januari } 2019\end{array}$ & $\begin{array}{r}\text { Analisi Problematika Anak Usia Dini } 3-5 \\
\text { Tahun Belum Mendapatkan Pendidikan } \\
\text { di PIAUD } \\
\text { Ayu Wirda Nengsi }\end{array}$ \\
\hline
\end{tabular}

untuk memperoleh proses pendidikan. Periode ini adalah tahun-tahun berharga bagi seorang anak untuk mengenali berbagai macam fakta di lingkungannya sebagai stimulans terhadap perkembangan kepribadian, psikomotor, kognitif maupun sosialnya. Berdasarkan hasil penelitian, sekitar 50\% kapabilitas kecerdasan orang dewasa telah terjadi ketika anak berumur 4 tahun, $80 \%$ telah terjadi ketika berumur 8 tahun, dan mencapai titik kulminasi ketika anak berumur sekitar 18 tahun (Direktorat PAUD, 2004). Hal ini berarti bahwa perkembangan yang terjadi dalam kurun waktu 4 tahun pertama sama besarnya dengan perkembangan yang terjadi pada kurun waktu 14 tahun berikutnya. Sehingga periode emas ini merupakan periode kritis bagi anak, dimana perkembangan yang diperoleh pada periode ini sangat berpengaruh terhadap perkembangan periode berikutnya hingga masa dewasa. ${ }^{6}$

Sementara masa emas ini hanya datang sekali, sehingga apabila terlewat berarti habislah peluangnya. Untuk itu pendidikan untuk usia dini dalam bentuk pemberian rangsangan-rangsangan (stimulasi) dari lingkungan terdekat sangat diperlukan untuk mengoptimalkan kemampuan anak.

Pendidikan anak usia dini tidak sekedar berfungsi untuk memberikan pengalaman belajar kepada anak, tetapi yang lebih penting berfungsi untuk mengoptimalkan perkembangan otak. Pendidikan anak usia dini sepatutnya juga mencakup seluruh proses stimulasi psikososial dan tidak terbatas pada proses

6 Slamet Suyanto. Konsep Dasar Pendidikan Anak Usia Dini. (Jakarta: Direktorat Jenderal Pendidikan Tinggi, 2005) hlm.5 pembelajaran yang terjadi dalam lembaga pendidikan. Pendidikan anak usia dini merupakan salah satu bentuk penyelenggaraan pendidikan yang menitikberatkan pada peletakan dasar ke arah pertumbuhan dan perkembangan fisik (koordinasi motorik halus dan kasar), kecerdasan (daya pikir, daya cipta, kecerdasan emosi, kecerdasan spiritual), sosio emosional (sikap dan perilaku serta agama) bahasa dan komunikasi, sesuai dengan keunikan dan tahap-tahap perkembangan yang dilalui oleh anak usia dini. $^{7}$

Berdasarkan penelitian yang telah dilakukan oleh Retno Wulandari, bahwa anak yang mengikuti PAUD dan memiliki perkembangan sesuai sebanyak 22 anak $(64,7 \%)$ dan memiliki perkembangan menyimpang atau tidak sesuai sebanyak 12 anak (35,3\%). Pada anak yang tidak mengikuti PAUD dan memiliki perkembangan yang sesuai sebanyak 9 anak (26,5\%) dan menyimpang atau tidak sesuai sebanyak 25 anak (73,5\%). Penelitian yang dilakukan terhadap 68 anak yang berusia antara 3-6 tahun di wilayah kerja Puskesmas Dukuhklopo Kecamatan Peterongan Jombang menunjukkan bahwa perkembangan sosial yang sesuai pada kelompok anak usia 3-6 tahun dengan pendidikan usia dini jauh lebih banyak sekitar 22 anak (64,7\%) dibandingkan dengan perkembangan sosial yang sesuai pada kelompok anak usia 3-6 tahun tanpa pendidikan usia dini sekitar 9 anak $(26,5 \%) .^{8}$

${ }_{8}^{7}$ Slamet Suyanto. ..hlm.8
${ }_{8}$ Retno Wulandari. Naskah Publikasi Perbedaan Perkembangan Sosial Anak Usia 3-6 Tahun Dengan Pendidikan Usia Dini Dan Tanpa 


\begin{tabular}{|r|l|r|}
\hline A1 Fitrah & Analisi Problematika Anak Usia Dini 3-5 \\
Journal Of Early Childhood Islamic Education & Tahun Belum Mendapatkan Pendidikan \\
di PIAUD \\
ISSN $:$ 2599-2287 E-ISSN $:$ 2622-335X \\
Vol.2 No.2 Januari 2019
\end{tabular}

Sedangkan perkembangan sosial yang tidak sesuai pada kelompok anak usia 3-5 tahun dengan pendidikan usia dini jauh lebih sedikit sekitar 12 anak (35,5\%) dibandingkan dengan perkembangan sosial yang tidak sesuai pada kelompok anak usia 3-5 tahun tanpa pendidikan anak usia dini sekitar 25 anak (73,5\%). Hasil tersebut dibuktikan dengan menggunakan ChiSquare didapatkan nilai p sebesar 0,002 $(\mathrm{p}<0,05)$. Hasil analisis tersebut dapat disimpulkan terdapat perbedaan yang bermakna. $^{9}$

\section{Analisis Problematika Anak Usia 3-5} Tahun Belum Mendapatkan Pendidikan Di PAUD

Di Indonesia pelaksanaan PAUD masih terkesan ekslusif dan baru menjangkau sebagian kecil masyarakat. Meskipun berbagai program perawatan dan pendidikan bagi anak usia dini usia (0-6 tahun) telah dilaksanakan di Indonesia sejak lama, namun anak usia 0-6 tahun yang memperoleh layanan perawatan dan pendidikan masih rendah. Data tahun 2001 menunjukkan bahwa dari sekitar 26,2 juta anak usia 0-6 tahun yang telah memperoleh layanan pendidikan dini melalui berbagai program baru sekitar 4,5 juta anak (17\%). Kontribusi tertinggi melalui Bina Keluarga Balita (9,5\%), Taman Kanak-kanak (6,1\%), Raudhatul Atfal (1,5\%). Sedangkan melalui penitipan anak dan kelompok bermain kontribusinya masing-masing sangat kecil yaitu sekitar $1 \%$ dan $0,24 \%$. $^{10}$

Pendidikan Usia Dini Di Kecamatan Peterongan Jombang. (Fakultas Kedokteran Universitas Muhammadiyah Surakarta, 2016) hlm.11

${ }_{10}^{9}$ Retno Wulandari........hlm.12

http://www.kpai.go.id/artikel/pemenuhan-hak-
Pendidikan Anak Usia Dini (PAUD) justru belum banyak mendapat perhatian. Pendidikan usia dini baru diperoleh oleh sebagian kecil anak di Indonesia. Pendataan Depdiknas pada tahun 2002, baru 28\% dari 26,1 juta anak usia 6 tahun yang mendapat pendidikan usia dini. Sebagian besar di antara mereka, yakni 2,6 juta mendapatkan pendidikan dengan jalan masuk ke Sekolah Dasar pada usia lebih awal (Enung, 2006). Indonesia memiliki fasilitas PAUD yang relatif sedikit. Situasi yang seperti ini menjelaskan mengapa orangtua cenderung untuk menyekolahkan anak-anak mereka lebih awal, sekitar 72\% anak usia enam tahun telah terdaftar di kelas 1 Sekolah Dasar. $^{11}$

Pada tahun 2004 tercatat bahwa jumlah APK-PAUD baru mencapai 12,7 juta (27\%) dan tahun 2008 APK-PAUD telah mencapai 15,1 juta $(50,6 \%)$ pada tahun 2009 akan mencapai 15,3 juta (53,6\%). ${ }^{12}$

Sebanyak 2,5 juta anak mendapat pendidikan di Bina Keluarga Balita (BKB), 2,1 juta anak bersekolah di TK atau Raidhatul Atfhal, dan sekitar 100.000 anak di kelompok bermain (play group). Rasio jumlah lembaga pendidikan dan anak usia dini diperkirakan 1:8. Data tersebut memperlihatkan bahwa Pendidikan Anak Usia Dini (PAUD) belum cukup mendapatkan perhatian padahal kapasitas

pendidikan-anak-sejak-usia-dini/, diakses pada tanggal 28 Oktober 2017

11 Retno Wulandari. Naskah Publikasi Perbedaan Perkembangan Sosial Anak Usia 3-6 Tahun Dengan Pendidikan Usia Dini Dan Tanpa Pendidikan Usia Dini Di Kecamatan Peterongan Jombang. (Fakultas Kedokteran Universitas Muhammadiyah Surakarta, 2016) hlm.5

$$
12 \text { Sumber }
$$

http://www.paud.kemdiknas.go.id 


\begin{tabular}{|l|l|r||}
\hline \multirow{2}{*}{\begin{tabular}{|l|l|} 
Al Fitrah \\
Journal Of Early Childhood Islamic Education
\end{tabular}} & $\begin{array}{r}\text { Analisi Problematika Anak Usia Dini 3-5 } \\
\text { Tahun Belum Mendapatkan Pendidikan } \\
\text { di PIAUD } \\
\text { ISSN : 2599-2287 E-ISSN : 2622-335X }\end{array}$ \\
Vol.2 No.2 Januari 2019 & Ayu Wirda Nengsi \\
\hline
\end{tabular}

perkembangan kognitif anak sudah dapat terbentuk pada usia dini jauh dibawah usia. Akses dan kualitas pelayanan PAUD sangat tidak seimbang, menurut UNICEF Indonesia (2012) menyampaikan kira-kira 62 persen anak usia 3 sampai 5 tahun belum pernah berpartisipasi dalam program pendidikan anak usia dini atau prasekolah. ${ }^{13}$

$$
\text { Masih rendahnya layanan }
$$
pendidikan dan perawatan bagi anak usia dini saat ini antara lain disebabkan masih terbatasnya jumla lembaga yang memberikan layanan pendidikan dini jika dibanding dengan jumlah anak usia 0-6 tahun yang seharusnya memperoleh layanan tersebut. Berbagai program yang ada baik langsung (melalui Bina Keluarga Balita dan Posyandu) yang telah ditempuh selama ini ternyata belum memberikan layanan secara utuh, belum bersinergi dan belum terintegrasi pelayanannya antara aspek pendidikan, kesehatan dan gizi. Padahal ketiga aspek tersebut sangat menentukan tingkat intelektualitas, kecerdasan dan tumbuh kembang anak. ${ }^{14}$

$$
\text { Pada Tahun 2015-2016, Angka }
$$

Partisipasi Kasar (APK) pada jenjang Pendidikan Anak Usia Dini (PAUD) merupakan yang terendah dibandingkan yang lainnya. APK siswa PAUD hanya mencapai 70,06\% dimana jumlah siswa PAUD pada Tahun Ajaran (TA) 2015/2016 mencapai 13,39 juta, sementara jumlah populasi usia 3-6 tahun mencapai 19,1 juta anak. ${ }^{15}$

$$
{ }_{14}^{13} \text { Retno Wulandari.........hlm.6 }
$$

http://www.kpai.go.id/artikel/pemenuhan-hak-

pendidikan-anak-sejak-usia-dini/, diakses pada tanggal 28 Oktober 2017

15 Kompas.Com. Angka Partisipasi Kasar Sekolah Berdasarkan Jenjang Pendidikan TA
Menurut Novan Ardy, Angka Partisipasi Kasar anak usia dini yang mengikuti/bersekolah di PAUD dengan yang tidak per propinsi di Indonesia pada tahun 2008 dapat dilihat pada tabel berikut ini: ${ }^{16}$
2015/2016.( di Publikasikan pada Kamis, 27 Oktober 2016), diakses pada tanggal 28 Oktober 2017

16 Novan Ardy. Konsep Dasar PAUD. (Yogyakarta : Gava Media, 2016) hlm. 11 


\begin{tabular}{|l|l|r|}
\hline \begin{tabular}{|l|l|} 
Al Fitrah \\
Journal Of Early Childhood Islamic Education
\end{tabular} & $\begin{array}{r}\text { Analisi Problematika Anak Usia Dini 3-5 } \\
\text { Tahun Belum Mendapatkan Pendidikan } \\
\text { ISSN : 2599-2287 E-ISSN : 2622-335X }\end{array}$ \\
Vol.2 No.2 Januari 2019 & Ayu Wirda Nengsi \\
\hline
\end{tabular}

Tabel 1. Angka Partisipasi Kasar Anak Usia Dini yang Bersekolah dan yang Tidak di PAUD per Propinsi di Indonesia Tahun 2008

\begin{tabular}{|c|c|c|c|c|}
\hline No & Provinsi & Usia 0-6 Tahun & $\begin{array}{l}\text { Siswa } \\
\text { PAUD }\end{array}$ & $\begin{array}{c}\text { APK } \\
\text { PAUD }\end{array}$ \\
\hline $1 \|$ & DKI Jakarta & 1.164 .583 & 496.470 & 42,63 \\
\hline 2 & Jawa Barat & 5.187 .613 & 2.023 .072 & 39,00 \\
\hline 3 & Banten & 1.369.724 & 431.118 & 31,47 \\
\hline 4 & Jawa tengah & 3.417.369 & 2.120 .069 & 62,04 \\
\hline 5 & DI Yogyakarta & 356.917 & 321.357 & 90,04 \\
\hline 6 & Jawa timur & 4.708 .453 & 3.596.988 & 76,39 \\
\hline 7 & NAD & 580.676 & 474.868 & 81,78 \\
\hline 8 & Sumatra Utara & 1.724 .233 & 474.247 & 27,50 \\
\hline 9 & Sumatra Barat & 563.646 & 348.949 & 61,91 \\
\hline 10 & Riau & 746.721 & 330.261 & 44,23 \\
\hline $11 \|$ & Kepulauan Riau & 117.351 & 91.054 & 77,59 \\
\hline 12 & Jambi & 619.101 & 317.792 & 51,33 \\
\hline 13 & Sumatra Selatan & 751.389 & 356.892 & 47,50 \\
\hline 14 & |Bangka Belitung & 131.186 & 112.002 & 85,38 \\
\hline 15 & Bengkulu & 217.499 & 115.550 & 53,13 \\
\hline 16 & Lampung & 954.847 & 439.869 & 46,07 \\
\hline 17 & Kalimantan Barat & 660.849 & 219.494 & 33,21 \\
\hline 18 & Kalimantan Tengah & 243.691 & 143.190 & 58,76 \\
\hline 19 & Kalimantan Selatan & 605.993 & 233.657 & 38,56 \\
\hline 20 & Kalimantan Timur & 600.879 & 200.868 & 33,43 \\
\hline 21 & Sulawesi Utara & 275.054 & 128.170 & 46,60 \\
\hline 22 & Gorontalo & 174.836 & 103.841 & 59,39 \\
\hline 23 & Sulawesi Tengah & 371.266 & 144.346 & 38,88 \\
\hline 24 & Sulawesi Selatan & 1.095 .025 & 494.996 & 45,20 \\
\hline 25 & Sulawesi Barat & 233.583 & 102.770 & 44,00 \\
\hline 26 & Sulawesi Tenggara & 333.223 & 214.802 & 64,46 \\
\hline 27 & Maluku & 279.506 & 89.928 & 32,17 \\
\hline 28 & Maluku Utara & 157.445 & 90.902 & 57,74 \\
\hline 29 & Bali & 429.384 & 193.878 & 45,15 \\
\hline
\end{tabular}




\begin{tabular}{|l|l|r|}
\hline \multirow{2}{*}{\begin{tabular}{||l|l|} 
A1 Fitrah \\
Journal Of Early Childhood Islamic Education \\
ISSN : 2599-2287 E-ISSN $: 2622-335 X$
\end{tabular}} & $\begin{array}{r}\text { Analisi Problematika Anak Usia Dini 3-5 } \\
\text { Tahun Belum Mendapatkan Pendidikan } \\
\text { di PIAUD } \\
\text { Vol.2 No.2 Januari 2019 }\end{array}$ \\
\hline
\end{tabular}

\begin{tabular}{|r||l||l||r||r||}
\hline \multicolumn{1}{|c||}{ No } & \multicolumn{1}{|c||}{ Provinsi } & Usia 0-6 Tahun & \multicolumn{1}{c|}{$\begin{array}{c}\text { Siswa } \\
\text { PAUD }\end{array}$} & \multicolumn{1}{c|}{$\begin{array}{c}\text { APK } \\
\text { PAUD }\end{array}$} \\
\hline 30 & Nusa Tenggara Barat & 564.741 & 321.079 & 56,85 \\
\hline 31 & Nusa Tenggara Timur & 715.464 & 208.537 & 29,15 \\
\hline \hline 32 & Papua & 317.530 & 99.863 & 31,45 \\
\hline \hline 33 & Papua Barat & 178.053 & 68.803 & 38,64 \\
\hline \hline \multicolumn{1}{|r|}{ Total } & 29.847 .830 & 15.109 .682 & 50,62 \\
\hline
\end{tabular}

Berdasarkan tabel 1 diatas, ternyata DI Yogyakarta memiliki APK PAUD sebesar 90,04\%. Dari sebanyak 356.917 anak usia dini, terdapat 321.357 anak usia dini yang terdaftar sebagai siswa PAUD. Dibandingkan dengan propinsi Jawa Barat yang memiliki APK PAUD sebesar 39\% sebanyak 5.187.613 anak usia dini terdaftar hanya 2.023.072 sebagai siswa PAUD.

Dari berbagai sumber diatas, hal ini membuktikan bahwa APK anak usia dini yang terdaftar sebagai siswa PAUD di Indonesia masih sangat minim, kesadaran akan pentingnya PAUD terhadap perkembangan anak usia dini belum sepenuhnya tumbuh, penyelenggaran program PAUD belum terrealisasikan secara sepenuhny, hal tersebut dipengaruhi oleh beberapa faktor tertentu.

\section{Faktor Penyebab Anak Usia 3-5 Tahun Belum Mendapatkan Pendidikan Di PAUD}

Keadaan tersebut sangat dipengaruhi oleh kesadaran masyarakat terhadap urgensi penyelenggaraan PAUD. Terdapat beberapa faktor penyebab anak usia 3-5 tahun belum mendapatkan pendidikan di PAUD antara lain:

1. Masih Terbatasnya Jumlah Lembaga PAUD

Terbatasnya jumlah lembaga PAUD, terutama di daerah-daerah pedesaan, daerah terpencil,dan daerah perbatasan. Pemerintah daerah harus mau dan mampu bekerja sama dengan pemerintah pusat dalam rangka mewujudkan program PAUD yang mengharuskan sebuah desa minimal memiliki satu lembaga PAUD. ${ }^{17}$ Indonesia masih kekurangan sebanyak 15.000 lembaga Pendidikan Anak Usia Dini (PAUD) untuk memenuhi target angka partisipasi kasar PAUD pada 2014 sebesar 75 persen, demikian dikatakan Dirjen PAUDNI Kemdikbud Lydia Freyani Hawadi. $^{18}$

2. Rendahnya Penerimaan Orang Tua Terhadap Penyelenggaraan PAUD

Belum semua orang tua dan masyarakat menyadari pentingnya PAUD. Rendahnya kesadaran masyarakat tersebut dapat dipengaruhi oleh beberapa faktor, misalnya faktor pendidikan orang tua, faktor ekonomi, maupun faktor sosial dan kebiasaan orang tua. Bahkan masih mudah ditemukan saat ini bahwa ada orang tua yang memaksakan kepada pendidik PAUD untuk mengajarkan baca, tulis, dan hitung (calistung). Hal inipun menjadi dilema yang kini tengah dihadapi oleh para pendidik PAUD.

${ }^{17}$ Novan Ardy. Konsep Dasar PAUD...hlm.

${ }^{18}$ Kompas.Com. Angka Partisipasi Kasar Sekolah Berdasarkan Jenjang Pendidikan TA 2015/2016.( di Publikasikan pada Kamis, 27 Oktober 2016), diakses pada tanggal 28 Oktober 2017 
Dalam latar belakang ekonomi orang tua juga diakui atau memiliki pengaruh yang besar terhadap kesadaran akan urgensi PAUD bagi putraputrinya. Orang tua dengan ekonomi menengah kebawah memandang jika menyekolahkan anaknya ke lembaga PAUD hanya akan menambah beban hidup mereka. ${ }^{19}$

3. Terbatasnya Sarana, Prasarana Dan Fasilitas Yang Dimiliki Oleh Lembaga PAUD

Hal ini juga menjadi pertimbangan yang kuat bagi orang tua untuk menyekolahkan anaknya dilembaga PAUD. Terkadang bagi orang tua apabila suatu lembaga memiliki sarana dan prasarana yang kurang, maka pembelajaran yang terjadipun tidak akan maksimal. ${ }^{20}$

4. Masalah Profesionalisme Pendidik PAUD

Pada peraturan Menteri Pendidikan Nasional Nomor 16 Tahun 2007 tentang Standar Kualifikasi Akademik dan Kompetensi Guru disebutkan bahwa kualifikasi akademik guru PAUD adalah minimum Diploma (D-IV) atau Sarjana (S1) dalam bidang pendidikan anak usia dini atau psikologi. ${ }^{21}$ Guru PAUD yang sudah S1 saat ini belum banyak. Sementara pengasuh untuk tempat penitipan anak dan pembimbing di kelompok bermain umumnya hanya berijazah SMA. Padahal untuk pengasuh dan pembimbing harus ditambah dengan

19 Novan Ardy. Konsep Dasar PAUD. (Yogyakarta : Gava Media, 2016) hlm. 10

${ }^{20}$ Kompas.Com. Angka Partisipasi Kasar Sekolah Berdasarkan Jenjang Pendidikan TA 2015/2016.( di Publikasikan pada Kamis, 27 Oktober 2016), diakses pada tanggal 28 Oktober 2017

21 Novan Ardy. Konsep Dasar

pendidikan PAUD tingkat dasar minimal.

Jumlah tenaga pendidik Pendidikan Anak Usia Dini tahun 2013 adalah 2916 guru. Dari jumlah tersebut hanya 845 guru yang memiliki ijazah sarjana. Hal ini seharusnya juga mendapat perhatian dari pemerintah agar program ini benar-benar berjalan sesuai dengan rencana program, sehingga mewujudkan PAUD yang menjangkau masyarakat kurang mampu dan tetap berkualitas. ${ }^{22}$

\section{Kesimpulan}

Angka Partisipasi Kasar (APK) anak yang bersekolah PAUD di Indonesia ini masih sangat minim, bahkan dalam penyampaian Direktur Jenderal Pendidikan Anak Usia Dini Nonformal dan Informal Kementerian Pendidikan dan Kebudayaan menyampaikan bahwa pada Tahun 2016 APK PAUD baru mencapai 34\%, sehingga perlu kerja keras untuk meningkatkan APK tersebut.

Berdasarkan tabel Angka Partisipasi Kasar anak usia dini yang mengikuti/bersekolah di PAUD dengan yang tidak per propinsi di Indonesia pada tahun 2008 dalam Novan Ardy ternyata DI Yogyakarta yang memiliki APK PAUD terbesar yaitu 90,04\%. Dari sebanyak 356.917 anak usia dini, terdapat 321.357 anak usia dini yang terdaftar sebagai siswa PAUD. Dibandingkan dengan propinsi Jawa Barat yang memiliki APK PAUD sebesar 39\% sebanyak 5.187.613 anak usia dini terdaftar hanya 2.023.072 sebagai siswa PAUD.

Dari pembahasan yang telah dibahas diatas, banyak hal yang membuktikan bahwa APK anak usia dini yang terdaftar sebagai siswa PAUD di Indonesia masih sangat minim, kesadaran akan pentingnya

${ }^{22}$ Kompas.Com .Angka Partisipasi Kasar Sekolah Berdasarkan Jenjang Pendidikan TA 2015/2016... 


\begin{tabular}{|l|l|r|}
\hline & Al Fitrah & Analisi Problematika Anak Usia Dini 3-5 \\
Journal Of Early Childhood Islamic Education & Tahun Belum Mendapatkan Pendidikan \\
di PIAUD \\
ISSN : 2599-2287 E-ISSN : 2622-335X \\
Vol.2 No.2 Januari 2019
\end{tabular}

PAUD terhadap perkembangan anak usia dini belum sepenuhnya tumbuh, penyelenggaran program PAUD belum terrealisasikan secara sepenuhnya.

\section{DAFTAR PUSTAKA}

http://www.kpai.go.id/artikel/pemenuhanhak-pendidikan-anak-sejak-usia-dini/

Kompas.Com. 2016. Angka Partisipasi Kasar Sekolah Berdasarkan Jenjang Pendidikan TA 2015/2016.di Publikasikan pada Kamis, 27 Oktober 2016

Lestari, Eko Sri. Analisis Program Pendidikan Anak Usia Dini (Paud) Di Kota Semarang. Skripsi S1 Fakultas Ilmu Sosial dan Ilmu Politik, Universitas Diponegoro Semarang

Suyanto, Slamet. 2005. Konsep Dasar Pendidikan Anak Usia Dini. Jakarta: Direktorat Jenderal Pendidikan Tinggi

Wiyani, Novan Ardy. 2016. Konsep Dasar PAUD. Yogyakarta : Gava Media

Wulandari, Retno. 2016. Naskah Publikasi Perbedaan Perkembangan Sosial Anak Usia 3-6 Tahun Dengan Pendidikan Usia Dini Dan Tanpa Pendidikan Usia Dini Di Kecamatan Peterongan Jombang. Fakultas Kedokteran Universitas Muhammadiyah Surakarta 